and 8. Perennial species have chromosome numbers of $2 n=8$ and $2 n=16$. Cytogenetic analyses of interspecific hybrids have demonstrated that those taxa with $2 n=16$ are tetraploids. This is indicated also by the four morphologically identical sets of chromosomes in the karyotypes. Interspecific diploid, perennial hybrids are usually 65 to 97 per cent fertile, and mostly bivalents are found at diakinesis. This evidence and that derived from analyses of certain hybrids indicated that the tetraploid taxa are segmental alloploids. The annual species have chromosome numbers of $n=2,3$, and 4. $H$. ravenii has $n=4$, and $H$. gracilis $(n=2$ and 3 ). Cytogenetic analyses of the $\mathrm{F}_{1}$ hybrid of $H$. gracilis $(n=2)$ and $H$. ravenii, in conjunction with ecological and geographical data, show that $H$. gracilis evolved from $H$. ravenii by a process of unequal reciprocal translocations and loss of centromeres. The race of $H$. gracilis with $n=3$ is not morphologically distinguishable from the $n=2$ race, and $2 n=5$ hybrids have been found in nature and producede artifically. Cylogenetic studies have shown that two chromosomes of the three-paired race are genetically equivalent to one chromosome of the two-paired race. In the $F_{1}$ hybrid preferential disjunction occurs from the trivalent so that the two chromosomes of the three-paired race always go to one pole and the genetically equivalent chromosome to the other pole during anaphase I of meiosis. The result is genetically balanced gametes with $n=2$ and $n=3$ and the possibility of reconstituting the parental and $F_{1}$ types in the $F_{2}$ generation. The mechanisms for the possible origin of the $n=2$ from the $n=3$ type and the converse were discussed.

\title{
SOME ASPECTS OF COMPOSITAE OF EVOLUTIONARY INTEREST*
}

\author{
Otto T. Solbrig (Ann Arbor) **
}

The family Compositae could have been used to illustrate all the problems that have been discussed during the three sessions of the Symposium. This is not surprising since it comprises almost $10 \%$ of all flowering plants, and has been the subject of many systematic and evolutionary studies.

Large range disjunctions, the subject of the first session of the symposium are found in many genera of Compositae. Among Pacific Basin genera, Celmisia, a widespread genus in New Zealand can be pointed out, since it is also found in the Andes of Perú, Ecuador, Colombia, and Venezuela. Another example is Lagenophora, found in Australia, New Zealand, and in South and Central America. Podocoma presents an unusual type of disjunction since two species grow in central and western Australia, two in the Andes of Colombia and Venezuela, while some ten species have been described from southern Brazil and Argentina. No biosystematic study has been made of Podocoma, but preliminary studies (Solbrig, unpubl.) indicate that it might be a case of convergent evolution in the one technical character of the genus (beaked achene), and not a case of true disjunction. Haplopappus and Solidago are representatives of another common pattern of range disjunctions: temperate South and North America. Solidago is represented in South America by only one native

* Including Chairman's remarks on the papers on the biosystematics of compositae.

** Department of Botany, University of Michigan, Ann Arbor, Mich. U.S.A. 
species that may represent a case of long range dispersal. Haplopappus on the other hand is represented in South America by a large number of species, and it is unlikely that they represent cases of long range dispersal.

Many species of Compositae are weedy, and are particularly good material for Biosystematic investigations. Baker's studies with Eupatorium and Ageratum (1965, and this symposium) are a case in point. Another case investigated by myself (Solbrig, $1965)$ is Erigeron maximus. This unusual Erigeron species formed by giant herbs 2 to $3 \mathrm{~m}$ tall, is found in Brazil and Paraguay (Solbrig, 1962) where it grows primarily in tropical and subtropical marshes and swamps, and is known by the common name of "marsh-daisy" (margarhida da banhao). Other populations (presumably ecotypes) are found at higher altitudes in the Serra do Mar, but as far as I could ascertain from my limited field studies, they are found in high altitudes always along water streams. Other habitats occupied by Erigeron maximus are roadsides and abandoned fields. Plants in these disturbed habitats are smaller in stature and in size of heads. Greenhouse observations indicate that these morphological differences are genetically fixed (table 1), and furthermore show that the weedy form blooms earlier and is selfcompatible. No change in chromosome number has accompanied the evolution of the weedy forms, all plants counted being octoploids with $n=36$, and they can (and apparently do) hybridize with the more narrowly adapted types.

Table I. Characteristics of three populations of Erigeron maximus studied under greenhouse conditions.

\begin{tabular}{|c|c|c|c|}
\hline Locality & Curitiba, Brazil & $\begin{array}{l}\text { Murumbi, Sao Paulo } \\
\text { Brazil }\end{array}$ & $\begin{array}{l}\text { Jardim Botanico } \\
\text { Sao Paulo, Brazil }\end{array}$ \\
\hline Environment & Swamp & Secondary growth & weed on lawn \\
\hline Date of germination & May 7, 1961 & May 7,1961 & May 7, 1961 \\
\hline No. of plants & 6 & 9 & 5 \\
\hline $\begin{array}{l}\text { Height of plant at } \\
\text { maturity }\end{array}$ & $150-270 \mathrm{~cm}$ & $45-180 \mathrm{~cm}$ & $90 \mathrm{~cm}$ \\
\hline Size of leaves & $45 \times 10 \mathrm{~cm}$ & $30 \times 9 \mathrm{~cm}$ & $30 \times 4 \mathrm{~cm}$ \\
\hline Surface texture & rough, scabrous & medium, scabrous & smooth to medium \\
\hline Date of flowering & August, 1962 & October, 1961 & August, 1961 \\
\hline Size of heads & $15-20 \mathrm{~mm}$ & $10-15 \mathrm{~mm}$ & $10 \mathrm{~mm}$ \\
\hline compatibility & incompatible & self-compatible & self-compatible \\
\hline chr. no. & $\mathbf{n}=36$ & $\mathrm{n}=36$ & $\mathrm{n}=36$ \\
\hline
\end{tabular}

Compositae are very fine material for studies of genecology and ecotypic differentiation, as Clausen, Keck, and Hiesey showed in their classical studies with Achillea, and the members of the subtribe Madineae of the Heliantheae. The large and cosmopolitan genus Aster is particularly well suited since a series of cytological and genetical phenomena are known to occur, such as aneuploidy, polyploidy (both auto- and allopolyploidy) and hybridization (Wetmore and Delisle, 1939; Avers, 1953; Solbrig, unp.). Figure 1 shows the known levels of polyploidy in the genus, with an indication of the presumed phylogeny. For the last two years, we have been conducting a series of chemical and biochemical studies to try to ascertain the correlations, if any, between 
cytological and genetical phenomena, biochemical processes, and ecotypic differentiation. Three major approaches are being pursued: investigation of the flavonoid biosynthetic pathways; physiology of anthocyanin production; and electrophoretic differentiation of leaf proteins.

Flavonoids are separated by paper and thin layer chromatography and identified by UV spectrophotometry. The pattern that has so far emerged is as follows. Certain compounds are present in all species of the genus, while others are specific of a species or group of species. A third group of compounds is present only in certain populations, or in certain plants within the population. These compounds may be correlated with adaptation to certain types of habitats, but so far there is no evidence for it.

For the studies of anthocyanin production, ten leaf-disks are grown for six days on a $1 \mathrm{M}$ sucrose solution under constant light, at $20^{\circ} \mathrm{C}$. The leaf disks are then cut into strips $1 \mathrm{~mm}$ in diameter, and extracted in a $0.1 \mathrm{M}$ solution of NCl for a week in a shaker in the cold. The amount of anthocyanin is determined colorimetrically using the Method of Thimann and Edmonson (1949). Species differ in their capacity of producing anthocyanin, as do populations within a species and individuals within a population. In the data obtained so far, there is a positive correlation between amount of anthocyanin and geographical locality: within a species plants from northern latitudes as well as higher altitudes produce the largest amounts of anthocyanin.

Chromosome numbers in the family have been investigated by us over the last eight years (Raven et al. 1960; Ornduff et al., 1963; Raven and Kyhos 1961; Solbrig et al. 1964; Payne et al. 1964) as well as by a number of other investigators (Turner et al. 1961 and previous papers). In concluding, and as a complement to the papers of Drs. Jackson and Huziwara who have addressed themselves to specific cytological phenomena in the tribe Astereae, I want to review the chromosomal picture in this tribe.

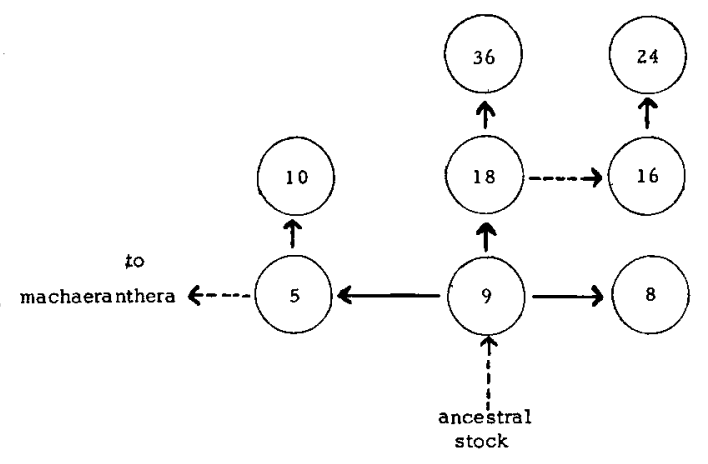

To date the chromosome numbers in about 500 of the 2000 species of the tribe have been determined, including species in 80 of the approximately 120 genera. The most frequent chromosome number in the tribe is $n=9$ or multiple of 9 , found in approximately $70 \%$ of the genera. Genera with species with $n=5$ comprise $30 \%$ of the genera, while $30 \%$ of the genera have species with $n=4$. (A genus often has species with different basic chromosome numbers, e.g. Aster, with species with $n=5$, 8 and 9). Genera with species with $n=5$ and $n=4$ are mostly formed by less than 20 species, are mostly annual in habit and are concentrated in the southwestern United States, and northern Mexico. Why this should be so is difficult to ascertain. It has been proposed (Solbrig, et al. 1964) that in the more extreme environment of 
this dry region, there is selection for lowered variability that will increase immediate fitness, following the hypothesis of Grant (1958). A lowered chromosome number would decraese recombination as a result of increased linkage, and might be of advantage to the species. Obviously this is not the only method to achieve increased immediate fitness, and other species have adapted to the desert without lowering their chromosome number. No experimental evidence in favor or against this hypothesis is available. The existence of species with different chromosome numbers within genera such as Aster, Haplopappus, and Machaeranthera, provides the material to test the hypothesis. A final unresolved problem is the bimodal distribution of the chromosome numbers in the tribe. One explanation offered (Turner et al. 1961) is that 4 and 5 represent the primitive condition and that species with 8 and 9 are allopolyploid derivatives. The low chromosome numbers are not positively correlated with primitive characteristics, and the likelihood of this hypothesis is low. Alternative explanations presuppose a gradual reduction of chromosome numbers by centric fusions from a primitive condition of $n=9$, or massive chromosomal rearrangements by a process of catastrophic evolution ${ }^{1}$ (Lewis 1966). Experimental evidence is needed to elucidate this problem also.

In summary, the Compositae are very suitable material for biosystematic investigations. Many scientists are actively studying the group, and I am confident that a clearer picture of the evolution of the family will soon be forthcoming.

\section{References}

Avers, Charlctte, J. 1953 - Biosystematic studies in Aster. I. Crossing relationships in the Heterophylli. Am. Journ. Bot. 40: 669-675.

BAKER, H. G. 1965 - Characteristics and Modes of Origin of Weeds. In Baker, H. G., and G. L. Stebbins, eds. "The Genetics of Colonizing Species", pp. 147-171. Academic Press, New York.

Grant, V. 1958 - The regulation of recombination in plants. Cold Spring Harbor Symposia Quant. Biol. 23: 337-367.

Lewis, H. 1966 - Speciation in Flowering Plants. Science 152-167-172.

Ornduff, R., P. H. Raven, D. W. Kyhos, and A. R. Kruckenberc 1963 - Chromosome numbers in Compositae III. Senecioneae. Am. Journ. Bot. 50: 131-139.

Payne, W. W., P. H. Raven, and D. W. Kyhos 1964 - Chromosome numbers in Compositae IV. Ambrosieae. Am. Journ. Bot. 51: 419-424.

Raven, H. H., O. T. Solbrig, D. W. Kyhos, and R. Snow 1960 - Chromosome numbers in Compositae I. Astereae. Am. Journ. Bot. 47: 124-132.

-- and D. W. Kyros 1961 - Chromosome numbers in Compositae II. Helenieae. Am. Journ. Bot. 48: 842-850.

SolbriG, O. T., 1962 - The South American species of Erigeron. Contr. Gray Herb. 191: 1-79.

- 1965 - Observations on the genecology of Erigeron maximus (Compositae). Arq. do Jardim Botanico, Rio, 18: 35-37.

-- , L. C. Anderson, D. W. Kyhos, P. H. Raven, and L. Rudenberg 1964 - Chromosome numbers in Compositae V. Astereae II. Am. Journ. Bot. 51: 513-519.

Thiman, K., and Y. H. Edmonson, 1949 - The Biogenesis of The Anthocyanins. I, General Nutritional Conditions leading to Anthocyanin formation. Arch. Biochemistry 22: 33-52.

Turner, B. L., J. M. Beaman, and H. F. Rock 1961 - Chromosome numbers in Compositae V. Fhodora 63: 121-129.

Wetmore, R. H. and A. L. Delisle 1939 - Studies in the genetics and cytology of two species in the genus Aster and their polymorphy in nature.

1 This last alternative was suggested by Dr. Harlan Lewis during the discussion of the papers of this Section. 